\title{
Gas-Phase Dimerization of Ethylene under Mild Conditions Catalyzed by MOF Materials Containing (bpy)Nill Complexes
}

Sherzod T. Madrahimov, ${ }^{\dagger, \|}$ James R. Gallagher, ${ }^{\ddagger}$ Guanghui Zhang, ${ }^{\ddagger}$ Zachary Meinhart, ${ }^{\dagger}$ Sergio J. Garibay, ${ }^{\dagger}$ Massimiliano Delferro, ${ }^{\dagger}$ Jeffrey T. Miller, ${ }^{\dagger}$ Omar K. Farha, ${ }^{*}, \dagger, \S$ Joseph T. Hupp, ${ }^{*}$, and SonBinh T. Nguyen*, $*$

${ }^{\dagger}$ Department of Chemistry, Northwestern University, 2145 Sheridan Road, Evanston, Illinois 60208, United States

${ }^{\ddagger}$ Chemical Sciences and Engineering Division, Argonne National Laboratory, 9700 S Cass Ave, Lemont, Illinois 60439, United States

${ }^{\S}$ Department of Chemistry, Faculty of Science, King Abdulaziz University, Jeddah, Saudi Arabia

\section{Supporting Information}

ABSTRACT: NU-1000-(bpy)Ni ${ }^{\text {II }}$, a highly porous $\mathrm{MOF}$ material possessing well-defined (bpy) $\mathrm{Ni}^{\mathrm{II}}$ moieties, was prepared through solvent-assisted ligand incorporation (SALI). Treatment with $\mathrm{Et}_{2} \mathrm{AlCl}$ affords a single-site catalyst with excellent catalytic activity for ethylene dimerization (intrinsic activity for butenes that is up to an order of magnitude higher than the corresponding (bpy) $\mathrm{NiCl}_{2}$ homogeneous analogue) and stability (can be reused at least three times). The high porosity of this catalyst results in outstanding levels of activity at ambient temperature in gasphase ethylene dimerization reactions, both under batch and continuous flow conditions.

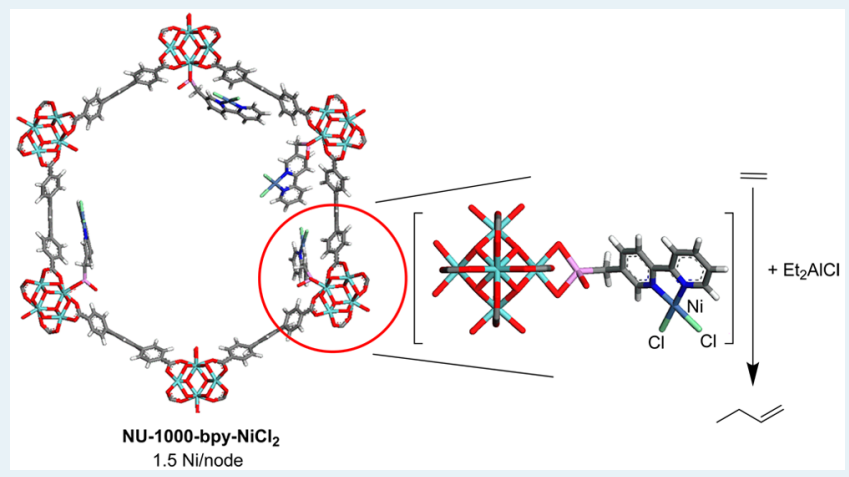

KEYWORDS: metal-organic framework, ethylene dimerization, gas-phase reaction, (bipyridyl)nickel complexes, catalysis

\section{INTRODUCTION}

In comparison to their heterogeneous counterparts, homogeneous transition metal catalysts generally have a more welldefined coordination environment that is made possible by discrete ligands. As a result, they can access reaction pathways that operate at lower energy regimes, their mechanisms can be studied more readily, and their activity profiles are easier to tune to afford better selectivity. ${ }^{1,2}$ At the same time, they tend to suffer from low thermal and chemical stabilities, while the need for a solvent in their operations limits their scope of reaction conditions (temperature range, phase compatibility, and recyclability, to name a few). Hence, the heterogenization of homogeneous molecular catalysts to improve their stability and reaction scope while preserving, or even enhancing, their tunability and activity-selectivity profile has emerged as one of the frontiers in modern catalysis. ${ }^{3-}$

Concurrently, with well-defined solid-state structures that include both discrete organic linkers and metal-ion/cluster nodes, metal-organic frameworks (MOFs) have recently emerged as a highly promising heterogeneous support for incorporating transition metal catalysts, ${ }^{8,9}$ either at the linker sites, ${ }^{10,11}$ directly on the nodes, ${ }^{12,13}$ or at ligand-modified nodes. ${ }^{14}$ These well-defined ligated sites offer a homogeneouslike coordination environment for metal species while the hybrid organic-inorganic nature of MOF allows one to extend their reaction scope to temperature ranges at least as high as $350{ }^{\circ} \mathrm{C},{ }^{12}$ much higher than the stability of many organic ligands, and to include gas-phase reactions. ${ }^{12}$ Yet for many MOF-based catalysts that have been studied to date, the slow transport of reactants and products in and out of the nanoscale pores of the MOF crystals can be a turnover-limiting factor. Even if every linker- or node-based site can be modified, reactions may only occur at surface-sites if the pore volume is small, especially in gas-phase catalysis. ${ }^{12,15}$ For cases when the pores are relatively large (1-2 $\mathrm{nm}$ in diameter), diffusion of substrates and products through large MOF crystals may still be slow, leading to observed induction periods, ${ }^{16}$ incomplete reactions, ${ }^{14,17}$ or side reactions of trapped products. ${ }^{18}$

The aforementioned challenges have led us to explore the catalysis potential of MOFs that also include pores larger than 2 nm. One of these, NU-1000, has a large pore channel (31 $\AA$ ) that has been shown to be a factor that accelerates catalysis in the solution-phase hydrolysis of the nerve-agent $O$-pinacolylmethylphosphonofluoridate (Soman) and a simulant. ${ }^{19}$ As such, we hypothesized that this platform can be extended to catalysis in the gas phase. Herein, we demonstrate that (bpy) $\mathrm{Ni}^{\mathrm{II}}$-functionalized $\mathbf{N U}-\mathbf{1 0 0 0}$ is a highly active catalyst for ethylene dimerization, an industrially important process due to a high demand for 1-butene in the production of low density

Received: July 25, 2015

Revised: September 19, 2015 


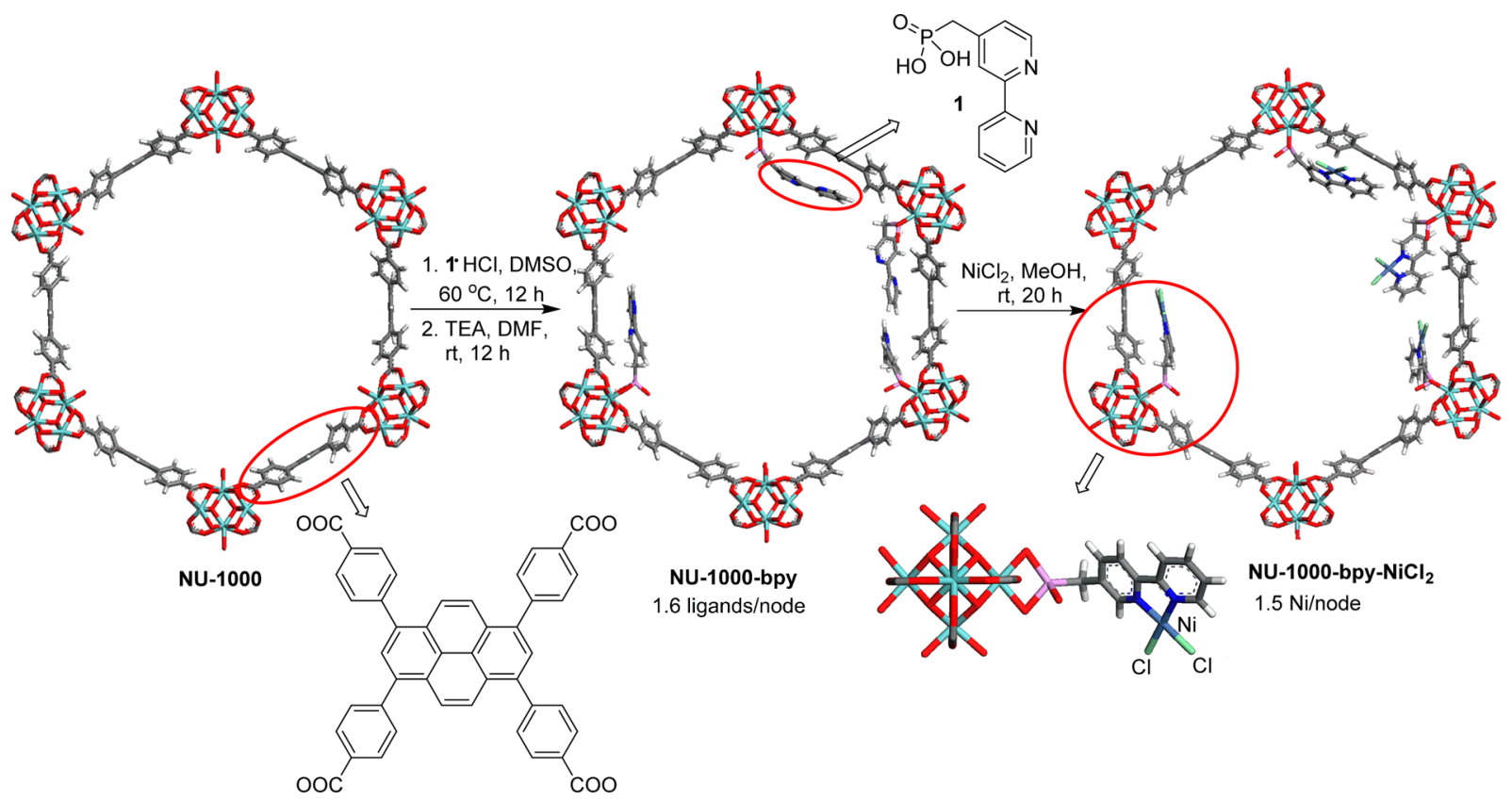

Figure 1. Preparation of NU-1000-bpy- $\mathrm{NiCl}_{2}$. The representations of the MOF framework were generated from the reported crystal structure ${ }^{21}$ using Materials Studio software version 5.

polyethylene. ${ }^{20}$ As such, it has been extensively studied in both solution and gas phases and can serve as a good model system for our investigation. In heptane, the NU-1000 support indeed reduces decomposition pathways for the catalyst, leading to intrinsic activities that are up to 1 order of magnitude better than that for the analogous homogeneous complex (bpy) $\mathrm{NiCl}_{2}$ and approaching those observed for $\left(\mathrm{PPh}_{3}\right)_{2} \mathrm{NiCl}_{2}$, one of the most active homogeneous ethylene dimerization catalysts. ${ }^{20}$ Most notably, (bpy) $\mathrm{Ni}^{\mathrm{II}}$-functionalized NU-1000, with its large mesopores, is highly active in the gas phase under both batch and flow conditions, allowing for the elimination of solvent and ease of separation of the reaction products.

\section{RESULTS AND DISCUSSION}

Preparation and Characterization of NU-1000-bpy$\mathrm{NiCl}_{2}$. NU-1000 can be made in gram quantities following our previously reported procedure. ${ }^{21}$ The $\mathrm{HCl}$ salt of the 5methylphosphonate-2,2'-bipyridine ligand 1 can also be prepared on a similar scale in $98 \%$ yield over two steps, following a strategy reported for the symmetric 5,5'-bis(methylphosphonate)-2,2'-bipyridine analogue ${ }^{22}$ (Figure 1, see Supporting Information (SI), section S3 for experimental and characterization details). Combining NU-1000 with a DMSO solution of $\mathbf{1} \cdot \mathrm{HCl}$ for $12 \mathrm{~h}$ (Figure 1 ; also see SI, section S4) readily afforded the desired NU-1000-bpyHCl material as an orange solid. ${ }^{23,24}$ This solvent-assisted linker incorporation (SALI) methodology took advantage of the ability of the $\mathrm{Zr}_{6}\left(\mu^{3}-\mathrm{OH}\right)_{8}(\mathrm{OH})_{8}$ nodes of NU-1000 to be readily modified through reaction between the free $\mathrm{Zr}-\mathrm{OH}$ moieties (or missing-linker sites) on the node and incoming carboxylic $^{23,24}$ or phosphonic acid ${ }^{25,26}$-containing functionalities. In contrast to the modifications with carboxylic acids, ${ }^{23,24}$ it was necessary to use a dilute solution and only a moderate excess (2.5-3 equiv $/ \mathrm{Zr}_{6}$ node) of the phosphonic acid ligand 1 to prevent decomposition of the NU-1000 framework during ligand incorporation. ${ }^{25}$
Analysis of NU-1000-bpyHCl by diffuse reflectance infrared Fourier transform spectroscopy (DRIFTS, see SI, Figure S3) clearly shows evidence of phosphonate modification of the terminal $\mathrm{Zr}-\mathrm{OH}$ sites of the $\mathrm{Zr}_{6}\left(\mu^{3}-\mathrm{OH}\right)_{4}\left(\mu^{3}\right.$ $\mathrm{O})_{4}(\mathrm{OH})_{4}\left(\mathrm{OH}_{2}\right)_{4}$ nodes $^{27}$ (henceforth referred to as $\mathrm{Zr}_{6}$ node for convenience). The terminal $\mathrm{Zr}-\mathrm{OH}$ stretch at 3674 $\mathrm{cm}^{-1}$ is strongly diminished compared to that for the parent NU-1000, suggesting near-complete reaction with the $\mathrm{HCl}$ salt of the phosphonate-bpy ligand $\mathbf{1}$. In addition, a broad $\mathrm{P}=\mathrm{O}$ stretch was observed at $\sim 1055 \mathrm{~cm}^{-1} \cdot{ }^{25}$ NU-1000-bpyHCl can be activated by heating the MOF under vacuum after exchanging the adsorbed DMSO with acetone. The ${ }^{1} \mathrm{H}$ NMR spectrum of activated NU-1000-bpyHCl that has been dissolved in a $\mathrm{D}_{2} \mathrm{SO}_{4} / \mathrm{DMSO}$ mixture showed an average incorporation of 1.7 bpyHCl moiety per $\mathrm{Zr}_{6}$ node (SI, Figure $\mathrm{S} 2$ ). While functionalization with $\mathbf{1} \cdot \mathrm{HCl}$ partially reduced the overall dimension of the mesoporous channel in NU-1000 (from 31 to $29.5 \AA$, see SI, Figure S4), NU-1000-bpyHCl remains highly porous (surface area $=1560 \mathrm{~m}^{2} / \mathrm{g}$, see SI, Figure S4) and crystalline (see SI, Figure S5 for powder X-ray diffraction (PXRD) data). The retention of the vertical feature at the beginning of the mesoporous region in the $\mathrm{N}_{2}$ adsorption/desorption isotherm (SI, Figure S4) suggests that the mesoporosity of the parent NU-1000 material was conserved. $^{25}$

Treating NU-1000-bpyHCl with a DMF solution of $\mathrm{NEt}_{3}$ over $12 \mathrm{~h}$ (Figure 1) results in complete deprotonation of the supported bpy moiety and with minimal loss of the supported ligand (1.6 bpy $/ \mathrm{Zr}_{6}$ node; see SI, section $\mathrm{S} 4$ for experimental details). The diffuse reflectance UV spectrum of the resulting NU-1000-bpy materials shows a clear red shift in comparison to those in the spectra of $\mathbf{N U}-1000$ and $\left[\mathrm{NU}-\mathbf{1 0 0 0}+\mathrm{NiCl}_{2}\right]$ (SI, Figure S6). As expected, the resulting free-base NU-1000bpy MOF remains highly porous (surface area $=1600 \mathrm{~m}^{2} / \mathrm{g}$, see SI, Figure S4) and crystalline (SI, Figure S5). Subsequent exposure of the orange NU-1000-bpy material to a solution of anhydrous $\mathrm{NiCl}_{2}$ in methanol ${ }^{28}$ then afforded NU-1000-bpy- 


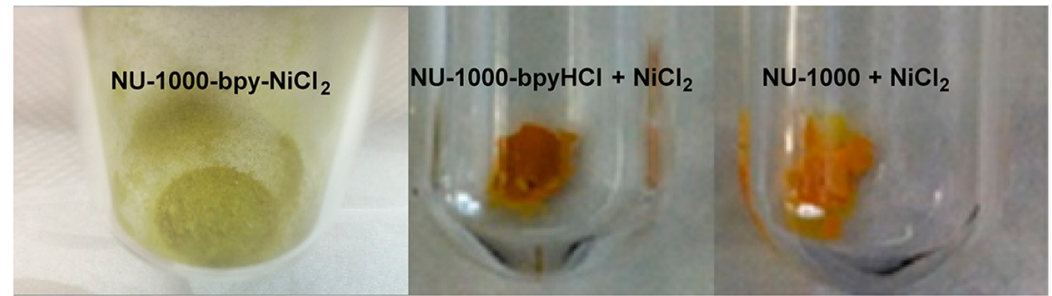

Figure 2. From left to right: Photos of samples of NU-1000-bpy, NU-1000-bpyHCl, and NU-1000 after reaction with methanolic $\mathrm{NiCl}_{2}$. The color of NU-1000 does not change after reaction with $\mathrm{NiCl}_{2}$.

Table 1. Product Compositions from Liquid-phase Ethylene Dimerization Reactions

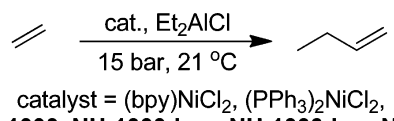

\begin{tabular}{|c|c|c|c|c|c|}
\hline entry & catalyst & $\begin{array}{l}\text { intrinsic activity (IA) for butenes } \\
\qquad\left(\mathrm{h}^{-1}\right)^{a, b, d}\end{array}$ & $\begin{array}{l}\text { butenes } \\
(\%)^{b}\end{array}$ & $\begin{array}{l}\text { hexenes }+ \text { octenes } \\
\qquad(\%)^{b}\end{array}$ & $\begin{array}{l}1-/ 2 \text {-butene } \\
\text { ratio }\end{array}$ \\
\hline 1 & $\begin{array}{l}\text { NU-1000 ( } 2.8 \mu \mathrm{mol} \text { of sites available for binding to bpy), } \\
1 \mathrm{~h}\end{array}$ & 0 & & & \\
\hline 2 & NU-1000-bpy (2.8 $\mu \mathrm{mol}$ bpy $), 1 \mathrm{~h}$ & 0 & & & \\
\hline 3 & (bpy) $\mathrm{NiCl}_{2}(2.8 \mu \mathrm{mol}), 1 \mathrm{~h}$ & $410 \pm 80$ & 91 & 9 & $90 / 10$ \\
\hline 4 & (bpy) $\mathrm{NiCl}_{2}(2.8 \mu \mathrm{mol}), 2 \mathrm{~h}$ & $255 \pm 50$ & 90 & 10 & $89 / 11$ \\
\hline 5 & (bpy) $\mathrm{NiCl}_{2}(35 \mu \mathrm{mol}), 1 \mathrm{~h}$ & 100 & 88 & 12 & $79 / 21$ \\
\hline 6 & $\left(\mathrm{PPh}_{3}\right)_{2} \mathrm{NiCl}_{2}(35 \mu \mathrm{mol}), 1 \mathrm{~h}$ & 7200 & 99 & $<1$ & $50 / 50$ \\
\hline 7 & NU-1000-bpy-NiCl $2(7.2 \mu \mathrm{mol} \mathrm{Ni}), 1 \mathrm{~h}$, first cycle ${ }^{e}$ & $1950 \pm 180$ & 93 & 7 & $91 / 9$ \\
\hline 8 & NU-1000-bpy-NiCl $2(4.7 \mu \mathrm{mol} \mathrm{Ni}), 1 \mathrm{~h}$, second cycle ce $^{c, e}$ & $6040 \pm 430$ & 94 & 6 & $91 / 9$ \\
\hline 9 & NU-1000-bpy-NiCl $2(1.4 \mu \mathrm{mol} \mathrm{Ni}), 1 \mathrm{~h}$, third cycle $^{c, e}$ & $1100 \pm 150$ & 95 & 5 & $93 / 7$ \\
\hline
\end{tabular}

NU-1000, NU-1000-bpy, NU-1000-bpy-NiCl

${ }^{a}$ Calculated based on the ratio between the amount of butenes formed and the Ni content of the catalyst. This number is only a lower limit of the intrinsic activity of the catalyst because it does not include the amounts of butenes that were converted into higher alkenes. ${ }^{b}$ The amounts of products formed were calculated from GC-FID analysis of the reaction mixture after in situ bromination. This number does not include either the very small amount of higher alkenes $\left(<1 \%\right.$ by GC-FID) or the small amount of polymer coating that was formed around the MOF crystals. ${ }^{c}$ The catalyst was reisolated from the previous reaction. A portion of it was removed for ICP-OES and SEM analyses, and the remainder was taken back into the drybox, retreated with $\mathrm{Et}_{2} \mathrm{AlCl}$ without removing the polymer residue from the catalyst, and reused for dimerization. ${ }^{d}$ Standard deviations for the IA data were calculated based on two runs for the homogeneous catalysts and three runs for the MOF-immobilized catalysts. Data for entries 5 and 6 were reported for one run and were in agreement with previously reported results. ${ }^{30}$ Entries $7-9$ comprise a series of "reuse" experiments where the catalyst is recovered after each experiment and split into two portions: one to be analyzed by ICP-OES, SEM, and GPC and the other to be reused. As such, the amount of catalyst is reduced after each step. However, these changes in loading should not affect the calculation of IA data given the high solubility of ethylene in hydrocarbon solvents (a 0.25 molar ratio to hexane (heptane should be similar) at 15 atm pressure of ethylene at room temperature) and the fact that our reactions were run under a constant supply of ethylene. ${ }^{33}$ Under these conditions, the amount of ethylene is about 3500 -fold in excess of our largest catalyst loading.

$\mathbf{N i C l}_{2}$ (Figure 1) as a green material (Figure 2, left vial), consistent with the presence of green (bpy) $\mathrm{NiCl}_{2}$ moieties. The diffuse reflectance UV-vis spectrum of NU-1000-bpy- $\mathbf{N i C l}_{2}$ shows an additional slight red shift of the main absorption peak $(\sim 410 \mathrm{~nm})$ with respect to that in the spectrum of NU-1000bpy (SI, Figure S6). Most notable is the broad absorption around $700 \mathrm{~nm}$ that is characteristic of the weak $\mathrm{d}-\mathrm{d}$ transition observed for (bpy) $\mathrm{NiCl}_{2}{ }^{29}$ Inductively coupled plasma atomic emission spectroscopy (ICP-OES) analysis indicates a stoichiometry of $\sim 1.5[\mathrm{Ni}] / \mathrm{Zr}_{6}$ node, suggesting a nearcomplete formation of supported (bpy) $\mathrm{NiCl}_{2}$ species. BET analysis of NU-1000-bpy- $\mathbf{N i C l}_{2}$ (SI, Figure S4) reveals a small decrease in specific surface area $\left(1450 \mathrm{~m}^{2} / \mathrm{g}\right)$ that is consistent with added density and narrowing of the mesoporous channel (to $28.5 \AA$ ).

As a control, the reaction of methanolic $\mathrm{NiCl}_{2}$ with NU-1000 shows much smaller $\mathrm{Ni}$ uptake $\left(0.4 \mathrm{Ni}{ }^{\mathrm{II}} / \mathrm{Zr}_{6}\right.$ node). The color of the isolated MOF after reaction is not distinguishable from that of NU-1000 (Figure 2 caption), consistent with a lack of (bpy) $\mathrm{Ni}^{\mathrm{II}}$ motif. A more significant uptake of $\mathrm{Ni}\left(1.1 \mathrm{Ni}^{\mathrm{II}} /\right.$ node) was observed for the reaction of $\mathrm{NiCl}_{2}$ with $\mathrm{NU}-\mathbf{1 0 0 0}$ -
bpyHCl; the isolated MOF becomes a bit darker than that of NU-1000 in color (Figure 2) but does not have the green color characteristic of $\mathbf{N U}-\mathbf{1 0 0 0}-\mathbf{b} p \mathbf{-}-\mathbf{N i C l}_{2}$. While these data indicated that some reactions may have occurred between the supported bpyHCl ligand, the level of nickelation is clearly not as high as for the reaction with the free-base NU-1000-bpy material.

Dimerization Reactions. Liquid-phase ethylene dimerization reactions were carried out at room temperature and under 15 bar of pressure of ethylene in heptane, following conditions used by Carnivet et al. for the (Fe)MIL-101- $\mathrm{NH}_{2}$-supported (pyridine-imine) $\mathrm{Ni}^{\mathrm{II}}$ catalyst, ${ }^{30}$ with suspended NU-1000-bpy$\mathbf{N i C l}_{2}$ as well as the appropriate controls (Table 1). Prior to the dimerization, all catalysts were pretreated with $\mathrm{Et}_{2} \mathrm{AlCl}(70$ equiv) to generate catalytically active nickel-hydrido moieties $^{31,32}$ (see SI, section S5 for experimental details and Figure S7 for a proposed catalytic cycle). For convenience of handling, the volatile products were brominated in situ prior to being analyzed by GC-FID.

As anticipated, neither NU-1000 nor NU-1000-bpy show any catalytic activity for ethylene dimerization (Table 1, entries 
1 and 2), thus ruling out the possibility of any background reaction in the absence of nickelated bipyridine. Molecular (bpy) $\mathrm{NiCl}_{2}$ displayed very low catalytic activity, consistent with a recent report; ${ }^{30}$ increasing the reaction time from 1 to $2 \mathrm{~h}$ only resulted in a significant decrease in the intrinsic activity (IA) for butenes (Table 1, entries 3 and 4), indicating that the (bpy) $\mathrm{Ni}^{\mathrm{II}}$ catalyst was rapidly decomposing during the ethylene dimerization. ${ }^{32}$ Increasing the (bpy) $\mathrm{NiCl}_{2}$ loading from 2.8 $\mu \mathrm{mol}$ to $35 \mu \mathrm{mol}$ also resulted in a decrease of the catalytic activity (Table 1 , entry 5 ), most likely due to limited solubility of the catalyst in heptane. In contrast, our NU-1000-bpy- $\mathbf{N i C l}_{2}$ catalyst is almost 1 order of magnitude more active for ethylene dimerization, with IAs and butene selectivities that are comparable to those reported for the (pyridine-imine) $\mathrm{Ni}^{\mathrm{II}}$ catalysts, which are more active than (bpy) $\mathrm{Ni}^{\mathrm{II}},{ }^{34-37}$ supported on (Fe)MIL-101- $\mathrm{NH}_{2}{ }^{30}$ and $\mathrm{Zn}_{4} \mathrm{O}(\mathrm{BDC})_{x}(\mathrm{ABDC})_{3-x}{ }^{38}$ MOFs. Moreover, immobilization of the (bpy) $\mathrm{Ni}^{\mathrm{iI}}$ catalyst on the MOF would prevent the decomposition of the catalytically active sites through transmetalation (SI, Figure S7). Notably, the activity for the $\mathbf{N U}-\mathbf{1 0 0 0}-\mathbf{b p y}-\mathbf{N i C l}_{2}$ catalyst persists over three cycles of reuse: its activity during the second cycle is actually more than 1 order of magnitude higher than that observed for (bpy) $\mathrm{NiCl}_{2}$ (Table 1 , cf entries 8 vs 3 ), approaching that of the more soluble and highly active homogeneous catalyst $\left(\mathrm{PPh}_{3}\right)_{2} \mathrm{NiCl}_{2}$ (Table 1 , cf entries 8 vs 6).

That the activity of the $\mathbf{N U}-\mathbf{1 0 0 0}-\mathbf{b p y}-\mathbf{N i C l}_{\mathbf{2}}$ catalyst is highest during the second cycle of reuse (Table 1, cf. entries 6 vs 7 vs 8 ) prompted us to analyze the catalyst after each oligomerization cycle. Interestingly, the mass of the solid material after the first cycle increased to $\sim 150 \mathrm{mg}$ from an initial catalyst weight of only $15 \mathrm{mg}$. PXRD analysis of this recovered material revealed it to be mostly highly crystalline polyethylene (PE) that was forming around crystals of the catalyst during the oligomerization reaction (SI, Figure S9). ${ }^{20,39}$ This PE is polydispersed and melted over a broad temperature range as shown by gel permeation chromatography (GPC) analysis (SI, Table S2) and differential scanning calorimetry (DSC; SI, Figure S10). Scanning electron microscopy (SEM) images of the recovered catalyst after the first ethylene dimerization (Table 1, entry 6) showed a morphology comprising porous-appearing, albeit polyethylene-covered, MOF crystals that were connected by a "web" of polyethylene (SI, Figure S11). The SEM images of the material that was recovered after the second cycle of catalysis (Table 1, entry 7) showed materials with more-solid PE coverage (SI, Figure S12). Analysis of the MOF crystals after removal of the polymer "coating" shows the size distributions to remain roughly the same before and after the first oligomerization (SI, Figure S13), suggesting that the changes in activity are not due to changes in crystal sizes (i.e., by breaking up the initial MOF crystals into smaller particles). In view of these data, we hypothesize that the increase in the catalytic activity after the first cycle is due to a layer of polymer forming on the surface of the MOF crystals after some reaction. This layer of polymer can preferentially increase the local solubility of ethylene near the MOF particles, leading to increase in IAs. However, as the amount of polymer increases (i.e., after the second reuse), it will block access to the active sites and decrease the oligomerization activity. We note in passing that formation of high-density polyethylene during oligomerization reactions in hydrocarbon solvents and in the gas phase have previously been observed for nickel-based catalysts used in the Shell higher olefin process (SHOP)..$^{20,39}$
The high IA observed in liquid-phase dimerization encouraged us to test the $\mathbf{N U}-\mathbf{1 0 0 0}-\mathbf{b p y}-\mathbf{N i C l}_{2}$ catalyst for gas-phase activity, which is highly attractive from the process perspective due to a complete elimination of solvent. Given the larger pores of NU-1000 and its ability to stabilize the active (bpy)Ni sites, we anticipated that the NU-1000-bpy- $\mathbf{N i C l}_{2}$ catalyst would also have excellent activities in the gas phase, although particle sizes, and thus catalyst site accessibility, may play more important roles in these reactions than analogous reactions in the solution phase. For the gas-phase reactions, two different samples of the NU-1000-bpy- $\mathbf{N i C l}_{2}$ catalyst, one assynthesized and another further crushed, were first treated with $\mathrm{Et}_{2} \mathrm{AlCl}$ in heptane and then isolated as dry solids (see SI, section S5 for further experimental details). Both were then separately exposed to 15 bar of ethylene for $1 \mathrm{~h}$, and the products of these reactions were analyzed by GC-FID after bromination. As expected for a sample with large polycrystalline platelets (several $\mathrm{mm}$ in size), the $\mathbf{N U}-\mathbf{1 0 0 0}-\mathbf{b p y}-\mathbf{N i C l}_{2}$ sample that was not crushed before $\mathrm{Et}_{2} \mathrm{AlCl}$ treatment showed minute catalytic activity in comparison to the crushed sample (Table 2 ,

Table 2. Data for the Gas-Phase Dimerization Reactions Catalyzed by NU-1000-bpy- $\mathrm{NiCl}_{2}$

\begin{tabular}{|c|c|c|c|c|c|}
\hline entry & catalyst & $\begin{array}{l}\text { intrinsic } \\
\text { activity (IA) for } \\
\text { butenes } \\
\left(\mathrm{h}^{-1}\right)^{a, e}\end{array}$ & $\begin{array}{l}\text { butenes } \\
(\%)^{b}\end{array}$ & $\begin{array}{l}\text { hexenes } \\
+ \\
\text { octenes } \\
(\%)^{b}\end{array}$ & $\begin{array}{l}1-/ 2- \\
\text { butene } \\
\text { ratio }\end{array}$ \\
\hline 1 & $\begin{array}{l}\text { crushed NU-1000- } \\
\text { bpy-NiCl } \\
\mu \text { mol })^{c}\end{array}$ & $1560 \pm 100$ & 82 & 18 & $57 / 43$ \\
\hline 2 & $\begin{array}{l}\text { as-synthesized } \\
\text { NU-1000-bpy- } \\
\mathrm{NiCl}_{2}(2.9 \\
\mu \mathrm{mol})\end{array}$ & $70 \pm 10$ & 83 & 16 & $85 / 15$ \\
\hline
\end{tabular}

${ }^{a}$ Calculated based on the ratio between the amount of butenes formed and the Ni content of the catalyst. This number is only a lower limit of the intrinsic activity of the catalyst because it does not include the amounts of butenes that were converted into higher alkenes. ${ }^{b}$ The amounts of products formed were calculated from GC-FID analysis of the reaction mixture after in situ bromination. This number does not include either the very small amount of higher alkenes $(<1 \%$ by GCFID) or the small amount of polymer coating that was formed around the MOF crystals. ${ }^{c}$ The MOF was crushed prior to activation with $\mathrm{Et}_{2} \mathrm{AlCl}$. ${ }^{d}$ The MOF was not crushed prior to activation by $\mathrm{Et}_{2} \mathrm{AlCl}$. ${ }^{e}$ Standard deviations for the IA data were based on two runs.

cf. entries 1 vs 2 ). This phenomenon is well-known in heterogeneous catalysis where samples with larger particles have smaller total external surface area and thus fewer accessible active sites. ${ }^{40}$ In the case of MOF-based chemistry, accessibility of substrates to the inner sites of crystals that are too large have been reported to be greatly improved when the crystals are ground into smaller-sized microcrystalline particles. $^{11,16}$

Notably, the crushed NU-1000-bpy- $\mathbf{N i C l}_{2}$ sample was remarkably active, with an IA that was only slightly lower than that observed for the analogous liquid-phase reaction (Table 2 , entry 1 vs Table 1 , entry 7 ). We speculate that the absence of solvent in this gas-phase batch condition is also a probable cause for the lower observed selectivity for butenes: without solvent, the local concentration of butenes inside the MOF pore may be quite high, and the 1-butene that formed would have more contact time with the MOF catalyst to undergo both isomerization (SI, Figure S7) and chain- 
lengthening during the time that the batch reaction was carried out. $^{41}$

The excellent activity of crushed NU-1000-bpy- $\mathbf{N i C l}_{2}$ in gasphase batch reactions prompted us to evaluate it under continuous flow conditions. $\mathrm{Et}_{2} \mathrm{AlCl}$-treated NU-1000-bpy$\mathrm{NiCl}_{2}$ was loaded into a vertical, $1 / 4^{\prime \prime}$ stainless steel tube reactor equipped with mass flow controllers and a constant flow of diluted ethylene ( $20 \mathrm{vol} \%$ in $\mathrm{He}$ ) was passed through the reactor at ambient temperature $\left(24^{\circ} \mathrm{C}\right)$ and pressure $(1 \mathrm{bar})$. A low flow rate of $13 \mathrm{~mL} / \mathrm{min}$ and dilute ethylene was used to avoid the buildup of a large exotherm, which is difficult to avoid in gas-phase olefin polymerization/dimerization processes. ${ }^{42}$ While a small exotherm was observed on introduction of the ethylene flow, with the temperature rising to about $28^{\circ} \mathrm{C}$, the reactor quickly equilibrated to ambient temperature. Excellent levels of conversion (95\%) were observed at the beginning of the reaction and remained high $(>80 \%)$ over the next $4 \mathrm{~h}$. The $95 \%$ level of conversion is quite remarkable because it would scale to an IA of $\sim 7500 / \mathrm{h}$ at 15 bar ethylene, ${ }^{43}$ at least 4 times better than the IA observed for our gas-phase batch system when corrected for the difference in ethylene concentrations. In comparison to the $180{ }^{\circ} \mathrm{C}$ temperature required for the gasphase olefin dimerization reaction catalyzed by $\mathrm{Ni}^{\mathrm{II}}$-based MOF materials, ${ }^{15}$ the molecular nature of our supported (bpy) $\mathrm{Ni}^{\mathrm{II}}$ species and the $\mathrm{Et}_{2} \mathrm{AlCl}$-pretreatment for activation are key factors for achieving high activity and butene selectivity at room temperature. The activity gradually decreased over the course of $20 \mathrm{~h}$ (SI, Figure S14), presumably due to a combination of catalyst deactivation and site blockage. Indeed, a pressure buildup in the flow reactor was observed concurrently with catalyst deactivation, with pressure increasing to 1.2 and $1.6 \mathrm{bar}$ after 5 and $20 \mathrm{~h}$, respectively. Similarly to that observed for the batch-scale reaction, SEM analysis of the catalyst recovered after the reaction under flow conditions indicated that the blocking of the flow can indeed be attributed to the formation of polyethylene around the MOF catalyst crystals (SI, Figure S15). ${ }^{20,39}$

In summary, we have shown that NU-1000 is a versatile MOF support for incorporating single-site catalysts. The MOFsupported (bpy) $\mathrm{Ni}^{\mathrm{II}}$ moieties showed ethylene-dimerization activities that are orders of magnitude higher than the corresponding homogeneous analog and good reuse potentials due to the immobilization-induced stabilization of the catalyst on the support. Most importantly, the availability of the large mesopores in NU-1000 facilitates gas-phase reactions both under batch and continuous flow conditions, allowing for gasphase conversions that rival solution-phase reactions. ${ }^{30}$ These data emphasize the need for incorporating mesoscale and larger pores to microporous supports to facilitate transport that can rival homogeneous catalysis.

\section{ASSOCIATED CONTENT}

\section{S Supporting Information}

The Supporting Information is available free of charge on the ACS Publications website at DOI: 10.1021/acscatal.5b01604.

General information, materials and methods, preparative procedure for the phosphonate-functionalized dinitrogen ligand $\mathbf{1}$ and $\mathrm{NU}-\mathbf{1 0 0 0}-\mathrm{bpy}-\mathrm{NiCl}_{2}$, and procedure for the oligomerization reactions (PDF)

\section{AUTHOR INFORMATION}

\section{Corresponding Authors}

*Tel: +1 847-467-4934. E-mail: o-farha@northwestern.edu.

*Tel.: +1 847-491-3504. E-mail: j-hupp@northwestern.edu.

*Tel: + 1 847-467-3347. Departmental Fax: +1 847-491-7713.

E-mail: stn@northwestern.edu.

\section{Present Address}

"(S.T.M.) Science Program, Texas A\&M University at Qatar, Texas A\&M Engineering Building 357, Education City, P.O. Box 23874, Doha, Qatar.

\section{Author Contributions}

S.T.M., O.K.F., J.T.H., and S.T.N. formulated the initial project and conceived the experiments presented herein. S.T.M. and Z.M. synthesized and characterized the starting materials and MOFs. S.J.G. synthesized some of the NU-1000-bpy- $\mathbf{N i C l}_{2}$ materials and carried out the diffuse-reflectance UV experiments. S.T.M. carried out all the reactions involving $\mathrm{Ni}^{\mathrm{II}}$ as well as the batch oligomerizations. J.R.G. and G.Z. carried out the continuous-flow, gas-phase dimerization reactions under the direction of J.T.M. M.D. obtained the GPC data for the polymer coating outside of the NU-1000 MOF crystals. O.K.F., J.T.H., and S.T.N. supervised the project. S.T.M. wrote the initial draft of the paper with contributions from all the coauthors. S.T.M. and S.T.N. finalized the manuscript. All authors have given approval to the final version of the manuscript.

\section{Notes}

The authors declare no competing financial interest.

\section{ACKNOWLEDGMENTS}

S.T.M. thanks the Camille and Henry Dreyfus Postdoctoral Program in Environmental Chemistry for financial support. Z.M. was supported by DTRA (grant No. HDTRA1-14-10014). Work by O.K.F. and J.T.H. was supported as part of the Inorganometallic Catalyst Design Center, an Energy Frontier Research Center funded by the U.S. Department of Energy (DOE), Office of Science, Basic Energy Sciences (BES), under award DE-SC0012702 (development of NU-1000 as a catalyst platform). S.T.N. and J.T.M. additionally acknowledge support from the U.S. Department of Energy, Office of Basic Energy Sciences, Division of Chemical Sciences, Geosciences, and Biosciences, under contract No. DE-AC02-06CH11357 (catalysis measurements and APS studies at Argonne). Experimental facilities at the Integrated Molecular Structure Education and Research Center (IMSERC), J. B. Cohen X-ray Diffraction Facility at the Materials Research Center, Keck II Facility, and the EPIC Facility of the NUANCE Center at Northwestern University are supported by the International Institute for Nanotechnology, NSF-MRSEC (grant No. DMR1121262), the Keck Foundation, the state of Illinois, and Northwestern University. We thank the reviewers of an initial version of this manuscript for helpful suggestions that improved it.

\section{REFERENCES}

(1) Astruc, D.; Lu, F.; Aranzaes, J. R. Angew. Chem., Int. Ed. 2005, 44, $7852-7872$.

(2) Hartwig, J. F. Organotransition Metal Chemistry: From Bonding to Catalysis; University Science Books: Sausalito, CA, 2010.

(3) Copéret, C.; Chabanas, M.; Petroff Saint-Arroman, R.; Basset, J.M. Angew. Chem., Int. Ed. 2003, 42, 156-181.

(4) McMorn, P.; Hutchings, G. J. Chem. Soc. Rev. 2004, 33, 108-122. 
(5) Shylesh, S.; Schünemann, V.; Thiel, W. R. Angew. Chem., Int. Ed. 2010, 49, 3428-3459.

(6) Sun, L.-B.; Liu, X.-Q.; Zhou, H.-C. Chem. Soc. Rev. 2015, 44, 5092-5147.

(7) Stalzer, M.; Delferro, M.; Marks, T. Catal. Lett. 2015, 145, 3-14.

(8) Farrusseng, D.; Aguado, S.; Pinel, C. Angew. Chem., Int. Ed. 2009, $48,7502-7513$.

(9) Lee, J.; Farha, O. K.; Roberts, J.; Scheidt, K. A.; Nguyen, S. T.; Hupp, J. T. Chem. Soc. Rev. 2009, 38, 1450-1459.

(10) Fei, H.; Shin, J.; Meng, Y. S.; Adelhardt, M.; Sutter, J.; Meyer, K.; Cohen, S. M. J. Am. Chem. Soc. 2014, 136, 4965-4973.

(11) Nguyen, H. G. T.; Weston, M. H.; Sarjeant, A. A.; Gardner, D. M.; An, Z.; Carmieli, R.; Wasielewski, M. R.; Farha, O. K.; Hupp, J. T.; Nguyen, S. T. Cryst. Growth Des. 2013, 13, 3528-3534.

(12) Nguyen, H. G. T.; Schweitzer, N. M.; Chang, C.-Y.; Drake, T. L.; So, M. C.; Stair, P. C.; Farha, O. K.; Hupp, J. T.; Nguyen, S. T. ACS Catal. 2014, 4, 2496-2500.

(13) Yang, D.; Odoh, S. O.; Wang, T. C.; Farha, O. K.; Hupp, J. T.; Cramer, C. J.; Gagliardi, L.; Gates, B. C. J. Am. Chem. Soc. 2015, 137, 7391-7396.

(14) Nguyen, H. G. T.; Weston, M. H.; Farha, O. K.; Hupp, J. T.; Nguyen, S. T. CrystEngComm 2012, 14, 4115-4118.

(15) Mlinar, A. N.; Keitz, B. K.; Gygi, D.; Bloch, E. D.; Long, J. R.; Bell, A. T. ACS Catal. 2014, 4, 717-721.

(16) Shultz, A. M.; Farha, O. K.; Adhikari, D.; Sarjeant, A. A.; Hupp,

J. T.; Nguyen, S. T. Inorg. Chem. 2011, 50, 3174-3176.

(17) Tanabe, K. K.; Allen, C. A.; Cohen, S. M. Angew. Chem., Int. Ed. 2010, 49, 9730-9733.

(18) Dhakshinamoorthy, A.; Alvaro, M.; Garcia, H. ACS Catal. 2011, $1,48-53$.

(19) Mondloch, J. E.; Katz, M. J.; Isley, W. C., III; Ghosh, P.; Liao, P.; Bury, W.; Wagner, G. W.; Hall, M. G.; DeCoste, J. B.; Peterson, G. W.; Snurr, R. Q.; Cramer, C. J.; Hupp, J. T.; Farha, O. K. Nat. Mater. 2015, $14,512-516$.

(20) Al-Jarallah, A. M.; Anabtawi, J. A.; Siddiqui, M. A. B.; Aitani, A. M.; Al-Sa'doun, A. W. Catal. Today 1992, 14, 1-124.

(21) Mondloch, J. E.; Bury, W.; Fairen-Jimenez, D.; Kwon, S.; DeMarco, E. J.; Weston, M. H.; Sarjeant, A. A.; Nguyen, S. T.; Stair, P. C.; Snurr, R. Q.; Farha, O. K.; Hupp, J. T. J. Am. Chem. Soc. 2013, 135, 10294-10297.

(22) Jurss, J. W.; Concepcion, J. C.; Norris, M. R.; Templeton, J. L.; Meyer, T. J. Inorg. Chem. 2010, 49, 3980-3982.

(23) Deria, P.; Mondloch, J. E.; Tylianakis, E.; Ghosh, P.; Bury, W.; Snurr, R. Q.; Hupp, J. T.; Farha, O. K. J. Am. Chem. Soc. 2013, 135, 16801-16804.

(24) Deria, P.; Bury, W.; Hupp, J. T.; Farha, O. K. Chem. Commun. 2014, 50, 1965-1968.

(25) Deria, P.; Bury, W.; Hod, I.; Kung, C.-W.; Karagiaridi, O.; Hupp,

J. T.; Farha, O. K. Inorg. Chem. 2015, 54, 2185-2192.

(26) Gelfand, B. S.; Lin, J.-B.; Shimizu, G. K. H. Inorg. Chem. 2015, 54, 1185-1187.

(27) Planas, N.; Mondloch, J. E.; Tussupbayev, S.; Borycz, J.; Gagliardi, L.; Hupp, J. T.; Farha, O. K.; Cramer, C. J. J. Phys. Chem. Lett. 2014, 5, 3716-3723.

(28) Kyogoku, K.; Yamada, C.; Suzuki, Y.; Nishiyama, S.; Fukumoto, K.; Yamamoto, H.; Indo, S.; Sano, M.; Miyake, T. J. Jpn. Pet. Inst. 2010, 53, 308-312.

(29) Shi, X.-M.; Wang, H.-Y.; Li, Y.-B.; Yang, J.-X.; Lei, C.; Ge, H.; Wei-Qing, X.; Bing, Z. Chem. Res. Chin. Univ. 2010, 26, 1011-1015.

(30) Canivet, J.; Aguado, S.; Schuurman, Y.; Farrusseng, D. J. Am. Chem. Soc. 2013, 135, 4195-4198.

(31) Roy, D.; Sunoj, R. B. Org. Biomol. Chem. 2010, 8, 1040-1051.

(32) Berkefeld, A.; Mecking, S. J. Am. Chem. Soc. 2009, 131, 15651574.

(33) Zhuze, T. P.; Zhurba, A. S. Bull. Acad. Sci. USSR, Div. Chem. Sci. (Engl. Transl.) 1960, 9, 335-337.

(34) Kinnunen, T.-J. J.; Haukka, M.; Pakkanen, T. T.; Pakkanen, T. A. J. Organomet. Chem. 2000, 613, 257-262.
(35) Ittel, S. D.; Johnson, L. K.; Brookhart, M. Chem. Rev. 2000, 100, 1169-1204.

(36) Tomita, T.; Takahama, T.; Sugimoto, M.; Sakaki, S. Organometallics 2002, 21, 4138-4146.

(37) Laine, T. V.; Lappalainen, K.; Liimatta, J.; Aitola, E.; Löfgren, B.; Leskelä, M. Macromol. Rapid Commun. 1999, 20, 487-491.

(38) Liu, B.; Jie, S.; Bu, Z.; Li, B.-G. RSC Adv. 2014, 4, 62343-62346.

(39) Kister, A. T.; Lutz, E. F. Oligomerization reaction system. U.S. Patent 4,020,121, April 26, 1977.

(40) Schlögl, R.; Abd Hamid, S. B. Angew. Chem., Int. Ed. 2004, 43, $1628-1637$.

(41) Andrei, R. D.; Popa, M. I.; Fajula, F.; Hulea, V. J. Catal. 2015, 323, 76-84.

(42) Ho, Y. K.; Shamiri, A.; Mjalli, F. S.; Hussain, M. A. J. Process Control 2012, 22, 947-958.

(43) The oligomerization under flow conditions was carried out at atmospheric pressure with a gas source that is only $20 \mathrm{vol} \%$ ethylene, 75 times less ethylene partial pressure than the conditions for the batch reaction (15 bar pure ethylene, both in solvent and gas-phase). As such, we multiply the activity of the flow reaction by 75 to compare with the batch reaction; this would make the IA at $95 \%$ conversion and 15 bar ethylene around $7500 / \mathrm{h}(98 \times 75)$. This estimate of $7500 / \mathrm{h}$ turnover is actually quite conservative considering that the solubility of ethylene in hydrocarbon solvents is very high (a 0.25 molar ratio to hexane under $15 \mathrm{~atm}$ of ethylene). 